\title{
Research for policy and practice in teacher education: The case of the Professional Practice Schools research project
}

\section{Maureen Robinson}

Department of Curriculum Studies, Stellenbosch University, Stellenbosch, South Africa mrobinson@sun.ac.za

https://orcid.org/0000-0003-1963-7629

(Received: 25 September 2020; accepted: 18 January 2021)

\section{Abstract}

This article starts from an acknowledgement of the complexity of connecting research, policy, and practice in teacher education. Using the framework of a practice architecture, I use a case study approach to explore how researchers, policy-makers, and teacher educators experienced a research project aimed at exploring the conditions for the establishment of Professional Practice Schools in South Africa. My discussion highlights the importance of seeing policy work as action-oriented inquiry, where the experiences of those directly involved in a policy are taken into central consideration. I outline enabling and constraining factors in supporting positive interconnections in this case study. I end the article by offering a hopeful view of conditions of possibility for further engagement between different sectors in the research-policy-practice nexus.

Keywords: research for policy, teacher education, educational practice

\section{Introduction}

South Africa has, over the last two decades, formulated a range of policies aimed at transforming the historical legacy of apartheid education. Within teacher education, this has included policies concerning governance and curriculum, as well as qualification pathways (Kruss, 2008; Sayed et al., 2013). In certain instances, the policy process has been relatively participatory, with government and academics interacting through bodies like the Education Deans' Forum. In other instances, such as, for example, the merger of institutions, policy has been initiated and planned by government, with teacher educators participating in implementation only.

In recent years, there has been renewed interest in research conducted by teacher educators on the implications and implementation of policies affecting them, with various researchpolicy-practice initiatives being established. These include: Research Chairs; projects on 
strengthening teacher education supported by the Department of Higher Education and Training and the European Union; commissioned research (Gravett et al., 2014; Robinson, 2015); research by para-statals and consultancies such as the Joint Education Trust (Deacon, 2016); as well as a number of edited collections of practice-oriented and self-study research by teacher educators (America et al., 2020; Sayed et al., 2018; Walton \& Osman, 2018).

A commitment to supporting productive links between research, policy, and practice in teacher education thus seems apparent. However, closer attention needs to be paid to the nuances and complexities of these links. The uncertain relationship between reform initiatives and policy implementation is well known, as McLaughlin (1987) has noted, yet authors have argued that little is known about knowledge mobilization as a research field (Cain et al., 2016). Common concerns are unreasonably high expectations of research, politics that play into policymaking and practice, and different orientations and values across sectors (Hammersley, 2013). The debate is also influenced by a global context which demonstrates an increasing call for evidence-based policies and quantifiable indicators of progress (Cain, 2016), a position that Biesta (2010) critiques as reducing complexity, and as being neglectful of professional judgement and values.

Against this background, I explore the relationship between research, policy, and practice in teacher education through the lens of one intervention, the Professional Practice Schools (PPSs) research project. This research project spanned all three of the domains of research, policy, and practice, and thus forms an interesting case study of the potentialities and tensions of this nexus.

\section{Professional Practice Schools as a policy intervention}

The proposal for the establishment of Professional Practice Schools (PPSs) emerged from a national Teacher Development Summit in 2009 that was held to highlight and address the challenges in teacher education and development in South Africa. The summit resulted in a new plan for teacher development in this country-the Integrated Strategic Planning Framework for Teacher Education and Development in South Africa 2011-2025

(Departments of Basic Education and Higher Education and Training, 2011). Activity 4.5 of this Integrated Plan specified the role of universities as being to strengthen the teaching practice/school experience component of teacher education programmes, with a key proposal being the development of Professional Practice Schools. PPSs were described as those schools at which student teachers are placed for the normal Teaching Practice component of their programmes. According to the plan, these schools would be located in a variety of social and educational contexts and display adequate levels of curriculum and organisational functionality. Furthermore,

[at] PPSs, student teachers will be able to engage in learning-in-practice-preparing, teaching and reflecting on lessons. Teachers at PPSs will mentor initial teachers in training, ensuring that they receive appropriate support and guidance during their practice teaching periods. Over time, sufficient PPSs will be identified and supported 
to ensure quality WIL [work integrated learning] for all initial teacher education students. PPSs will also be utilised as hubs for the development of professional learning communities. (DBE \& DHET, 2011, p. 18)

No further details or conceptual underpinnings for the initiative were provided in the policy document. Nevertheless, the thinking behind such a proposal would appear to resonate with the notion of a "third space" (Zeichner, 2010, p. 89) in teacher preparation, in which practitioner knowledge and university knowledge are brought together to create expanded and grounded learning opportunities for student teachers.

The intention was that PPSs would be identified from within the ambit of existing schools and it was thus important to understand what needed to be in place to be able to designate an existing school as a PPS. A research project was therefore commissioned by the national Department of Higher Education and Training (DHET) to explore the conditions for the establishment of such schools. The aims of the research were to identify and make recommendations regarding

a. Minimum standards for effective functional PPSs in a variety of social and educational environments, including poor and rural contexts

b. Key curriculum and organisational factors impacting on the school-based experience of student teachers

c. Partnership models to support the relationship between PPSs, universities and education departments

d. Resource, training and policy requirements for the effective functioning of PPSs

e. A conceptual framework to support the development of PPSs. (Robinson, 2015, p. 5)

Between 2013 and 2014 nine universities, five primary schools, and thirteen high schools in five provinces of South Africa-the Eastern Cape, Gauteng, Kwazulu-Natal, Limpopo and Western Cape-participated in the research. Ethical approval was received from all participating universities and provincial departments of education. Data was generated primarily through interviews with mentor teachers and principals at schools, officials in the provincial and national Departments of Education, and university-based Teaching Practice supervisors. A final report was submitted to DHET in 2015. The findings were then presented and discussed at several national and provincial workshops and conferences at which key stakeholders participated.

\section{Framing the study}

The research-policy-practice nexus of this study can be said to embody a particular set of interlocking professional domains and practices. Kemmis (2009) has argued that the study of a practice like education involves

a study of connections - of many different kinds of communicative, productive and organisational relationships between people in socially-, historically- and 
discursively-constituted media of language (discourse), work and power-all of which must be understood dynamically and relationally. (Kemmis, 2009, p. 24)

This relational view of practice invites us to understand the arrangements, or architecture, that hold (or fail to hold) the practice together. A practice architecture refers to the "complex bundlings of arrangements of mediating pre-conditions of practice, ways of saying, doing and relating, and objects and set-ups with which people in the setting interact" (Kemmis, 2009, p. 34). These preconditions of practice (the "exoskeleton' of the practice) include

cultures and discourses, social and political structures and dynamics, and material and economic conditions under which a practice is practiced ... [and which] enables or constrains particular characteristic modes of professional practices, as well as local variations on their more general forms. (Kemmis, 2009, p. 33)

Three aspects form the core of such an architecture.

1. In semantic space, the sayings of our practices are intertwined with cultural-discursive arrangements (in language and specialist discourses) that enable and constrain what we say and how we think.

2. In physical space-time, the doings of our practices are intertwined with materialeconomic arrangements (in the medium of activity and work) that enable and constrain where we can go and what we can do.

3. In social space, the relatings of our practices are intertwined with social-political arrangements (in the medium of power and solidarity) that enable and constrain how we can relate to others and the world. (Kemmis, 2018, pp. 243-244)

By its very nature, the research touched on the different professional life worlds of these different players - such worlds simultaneously intersecting with, and independent of, one another. How the interviewees, from their different perspectives, experienced the culturaldiscursive, material-economic and social-political factors embedded in the PPSs research project provided the framework for the analysis of the data.

\section{Methodology}

The purpose here is not to outline the findings of the commissioned research (see Robinson (2016) for the findings) but, rather, to discuss the PPSs research as a case study that can illuminate the tensions and opportunities of research of this nature in its interaction with policy and practice. In this sense, the research serves as an instrumental rather than an intrinsic case study since the purpose is to surface broader issues beyond the case, rather than to focus on the specifics of the case itself (Rule \& John, 2011).

Various reasons support the selection of this case. First, the research had been commissioned by the government ministry responsible for teacher education, thus providing a clear example of research for policy. Second, the policy was intended for systemic impact since its purpose was to foster long-term structural change in teacher education, rather than as a smaller 
programmatic innovation. This is set against a concern about the small-scale and localised nature of much research into teacher education (Cochran-Smith et al., 2015; Deacon et al., 2010). Third, developments were emerging at both national and provincial level and could be tracked beyond the finalisation of the PPSs research report.

Green et al. (2017) have argued that mainstream education policies treat teacher education as an instrumental field to be managed through regulation, legislation, codification, measurement, and standardisation. In contrast, they call for policy work to be conceptualised as action-oriented inquiry with respect to the primacy of practice, in all its complexity (Green et al., 2017). From this perspective, the PPSs research project deliberately sought to explore the views of those on-the-ground players who were directly and actively involved in the practice of the policy proposal, namely education department officials, teacher educators, and teachers.

Twelve interviews were conducted with these key informants; participant observation of relevant networks and forums provided further perspectives. Other than the national representatives, all interviewees were based in the Western Cape, and included

- Six policy-makers - three in the national Department of Higher Education and Training (one who was involved in conceptualising the Integrated Strategic Plan, one who had commissioned the PPSs research, and one responsible for the implementation of the research); two in the provincial Department of Education involved in the implementation of the research at local level; and one who had been an academic in the original research team but who had recently relocated to a government position;

- Four university-based teacher educators, two from the original research team (as well as the one additional person who had now moved to a government position), and two who were responsible for the Teaching Practice programme at their own universities; and

- Two teacher union representatives, responsible for professional development amongst practising teachers.

Most of the interviewees were active participants in a statutory network established by the DHET in each province to enhance dialogue about teacher education (the Provincial Teacher Education and Development Committee); a number had also participated in national processes aimed at improving Teaching Practice in the country. The porous positioning of the interviewees meant that they could offer insights from different perspectives, thus allowing interesting cross-pollination across roles.

Initially the intention was to analyse the data according to all three aspects of practice architecture as identified by Kemmis (2018). However, it became apparent that findings, as gathered through interviews, could not provide sufficient insights into all three of these aspects of the research intervention. Thus, the analysis moved to what the interviewees said about the cultural-discursive, material-economic, and social-political arrangements of the 
research. The data thus records the perspectives of the different role-players of the researchpolicy-practice relationship in this research project.

\section{Sayings}

In this section, I report first on what participants said about their expectations of the research. Responses were consistent across the interviewees; this revolved around the value perceived of providing "evidence for a conversation" that could inform both policy and practice. One teacher educator was of the view that "up to now there has been very little empirical evidence around any of the issues relating to PPSs." From an academic point of view, she felt that research-based evidence carried a higher status than arguments derived from practice-based knowledge. She said, "People don't listen to you unless you have evidence. The document gave one the tools to start a conversation ... research findings [are able] to influence our academic conversations."

For one policy-maker looking for concrete outcomes, evidence provided a basis for "a set of recommendations as it takes the next step forward toward the establishment of the PPSs." The teacher educator had a more nuanced expectation in her wish to know "what the possibilities are ... what the issues and tensions are."

Interviewees were also asked about their motivation to participate in the research. A clear action-oriented agenda underpinned everyone's motivation to participate in that the research was seen as offering insights to improve teacher education through, first of all, addressing a perceived "theory-practice" gap between schools and universities. "There was a sense that university preparation is not strong enough, there is a necessity to create more of a reality experience" (policy-maker); "there was a perception that there is too much theory in the academic programme" (union representative); the research "can really address the gap in communication between the universities and the schools, [this] breaks down the quality of Teaching Practice" (teacher educator). Schools, too, were seen as potential beneficiaries of the findings of the research that can help to "identify a school that can really be supportive of helping student teachers to become quality teachers" (policy-maker).

\section{Sayings about doings}

Here the material-economic arrangements of the research were explored; this involved probing interviewees' views on the nature of the research process.

On the nature of the research, participants were very enthusiastic. They appreciated that the research was action-oriented, and that a research partnership had been set up between the university and the Department of Education to inform the implementation of policy and, in the longer term, to enhance teacher education. The execution of the research by a universitybased team was seen as supporting sustainability. For a policy-maker, "If the research is led from within the sector, there is a greater likelihood of strong buy-in, support and participation from the sector." 
Interviewees' comments on the nature of the research process revealed interesting aspects of their own professional worlds. One policy-maker had valued the opportunity to read about the views of teachers, and the open-ended questions raised since our "focus is usually about meeting targets, policy compliance, to show things are working." Another policy-maker found the qualitative research methods different from what he was used to. He said, "We like data and figures and numbers and then we use that." The visits to the schools around the country were illuminating for one university-based researcher, who valued time in the field and explained, "I like to not only talk to people but have a lived experience to see what is happening."

Less positive were the responses about the material conditions (time and capacity) for conducting the investigation, particularly as expressed by the university researchers. As one teacher educator indicated, "You can't combine this kind of project with a normal teaching and admin load." This resonates with accounts of the social organisation of the work of teacher educators in other parts of the world, as McNicholl et al. (2013) have observed.

The most significant response in relation to doings was whether participants had drawn on the research in their own practice. Despite the expressed enthusiasm about the practiceorientation of the research, two years after its conclusion, while there had been references to the research in conversations, workshops, and small projects, none of the interviewees indicated that they had drawn on the research in any systematic way.

\section{Sayings about relatings}

On social-political arrangements, interviewees offered their views on the systems and processes for carrying forward the findings of the research.

Two different perspectives were articulated by interviewees - one about discourses, and the other relating to implementation, with the former being more positively experienced.

When they were asked about the potential contribution of the research, interviewees were very enthusiastic. They felt that the research had helped to clarify concepts, informed both policy and practice, leveraged the teacher unions, helped to establish more structured relations between schools and universities and between universities and the Department of Education, and (a point emphasized by many) started a conversation. Debate and discussion had been promoted and further required research and action identified. As one teacher educator expressed it, "We became aware of possibilities for the future." The integration of the academic and policy world was seen to offer potential to both theory and practice. "We need to align our theoretical points of departure with the practical realities out there," said a former teacher educator, now a policy-maker.

In providing what someone called "evidence for a conversation" participants identified a professional as well as a political contribution. The potential for a professional contribution was unambiguous: "The research provides clear recommendations" (researcher); "It has provided a framework for discussion" (teacher educator); "It has created a collaborative space 
to devise solutions for the many challenges that are facing good Teaching Practice" (policymaker); "It is vital to build up a scholarship of teacher education and for this scholarship to be used to critique and inform practice" (policy-maker).

The union representative was particularly positive about the political contribution of the research. She said, "We can't just decide on something because it is politically correct and then there is a mandate; we need research." She added, "[The research] provides leverage; the Department is not going to listen to anybody unless there is sound proof." She also expressed appreciation for the writing style of the report, saying "It is user-friendly. Lots of academic work is not written like that and for the teacher in the classroom, they are able to read and understand it." One policy-maker, perhaps taking the opportunity to move out of his usual role, was more cynical about the political contribution and said, "The research is meant to justify policy positions."

While the overall feeling about the research was very positive, doubts were expressed about implementation. Three comments from policy-makers indicated scepticism about the potential of research to influence any change. They said: "If people's mindsets don't want to change, then all our research is null and void"; "Nobody wants to see data, they seem to think there are more important things to be sorted out by government"; and "Unless an official has a passion for Teaching Practice, nobody will read it."

The limitations of the policy structures to review and follow through on the recommendations of the research were apparent. As one provincial policy-maker expressed it, "We do not have research staff ... the focus is on delivery, on operational things ... What we do is monitor and evaluate, not focus on deep research, deep understanding and then have the ability to change things afterwards." He elaborated further, "Most research projects only deal with compliance and delivery. Can we push up the results, etc."

Even at national level, research structures were described as "lean in their capacity for doing dedicated research." As was further articulated, "There are no specific structures for policyoriented research on teacher education . . Policy-oriented research is promoted and enabled on a needs basis and is often dependent on the availability of funds to support the research." Despite these constraints, one policy-maker remained positive about the potential contribution of research: "Policy and practice must be evidence-based . . . we must move beyond anecdote and common-sense approaches to what we do, and how we understand the sector ... It is vitally important to build up a scholarship of teacher education, and for this scholarship to be used to critique and inform practice."

The union representatives were sober about the capacity of schools to absorb the findings of the research. One said, "Teachers at school are captured by policy demands . . . there are too many policy requirements." Another believed that "schools don't have time to have these discussions ... The system does not allow for reflection or discussion." As a union representative said, "If you don't have a budget, you are setting up policy for failure. That is what happens in teacher development." 
For one teacher educator, implementation would depend on "money, resources and time," all of which she saw as being in short supply. The implications for action were also treated with some scepticism by another, who said, "I would look at it as a nice research document and it would sit in my office but to be involved in it would be so difficult because it is so complex."

\section{Discussion}

While all participants expressed satisfaction with the recommendations of the research, and appreciation for the valuable conversations, three years later there was little actual movement on the proposal to establish PPSs. A few initiatives had emerged; there was, for example, an online teacher mentor programme and a protocol for Teaching Practice in one province, and several national workshops and Round Tables towards enhancing Teaching Practice had been held, but no planning at systemic level had occurred.

A relational architecture that can "promote, sustain and extend meaningful actions and interactions across interpersonal and institutional levels" (Edwards-Groves et al., 2010, p. 53) is influenced by factors that both enable and constrain. The findings from the interviews reveal several factors that enabled and constrained the building of a productive relationship between research, policy, and practice in the PPSs research project. At an enabling level, it was clear that there was a commitment across the board to the research, strong motivation to participate, communication and trust across the sectors, positive relationships, an appreciation of the value of collaboration, as well as support and resources from formal policy structures. At a constraining level, however, weak capacity existed in all sectors for mediating or implementing the findings of the research. For the teacher educators these constraints revolved around fitting new initiatives into an already demanding academic workload, for the policy-makers, the structures to follow through on research findings were largely absent, and the teachers themselves were faced with overload in both practical and policy demands.

In the language of practice architecture, then, one could say that the interaction of research, policy, and practice in this case study demonstrated lots of saying, quite a bit of relating, but not much doing. Put differently, the research had significantly advanced the discursive and social arrangements of the policy intervention but had not strengthened its material and economic arrangements.

These findings clearly highlight the difficulty of promoting a productive research-policypractice nexus. A first lesson, then, is the need to acknowledge the limitations of research processes and outcomes and to accept that research is but one resource in a multi-layered interplay of factors in policy development and practical implementation. The limitations of research evidence to impact on policy and practice have indeed been consistently argued (Ball, 1998; Biesta, 2010; Hammersley, 2013). As Hammersley (2013, p. 9) put it, “[A] sound evidential base is not all that is required for practical success." The dynamics at play in the research-policy-practice interaction are fluid and complex, and

[t]he project of evidence-based practice therefore urgently needs to be rethought in ways that take into consideration the limits of knowledge, the nature of social 
interaction, the ways in which things can work, the processes of power that are involved in this, and most importantly, the values and normative orientations that constitute social practices such as education. (Biesta, 2010, p. 501)

While the above might constitute a sense of disillusionment regarding the PPSs research project, from an action-oriented position on policy formation, a greater sense of hope can be distilled. Conversations, debates, and dialogues across sectors had generated respect for the lived experience of the different sectors, a sense of mutual reciprocity and accountability for the process, and a vocabulary for further engagement. In this way, the PPSs research project contributed in a small way to the establishment of a relational architecture, characterised by respectful interpersonal and organisational connections, as well as what Edwards (2011, p. 37) called "knowledge talk at the boundaries."

Such connections and relationships, while positive, are clearly not able to offer a toolkit for implementation. Nevertheless, they are important to the notion of action-oriented inquiry. By recognising experiences, insights, and interpretations of those involved in articulating and enacting the policy and the practice, we are able to challenge "a reliance only on inanimate, disembodied, institutional representations of policy" (Green et al., 2017, p. 55) and to work from the starting point of the primacy of practice. From this perspective, small-scale local initiatives take on greater significance. Even where conditions make it difficult to move to scale, relational agency (Edwards, 2005) is built, joint responsibility across sectors is acknowledged, and the resources (and limitations) of different players identified, all of which bodes well for further engagement.

\section{Conclusion}

In this article, I have outlined the findings of research into the relationship between research, policy, and practice in the identification and establishment of Professional Practice Schools in South Africa. Although a single case study, the findings are intended to go beyond the immediate context and to generate questions for further conversation, reflection, and research. The discussion thus pays attention to the complexity and particularity of the individual case as well as to its generative potential for insights beyond the immediacy of the case itself (Rule and John, 2015).

Kemmis (2018) has reminded us that the conditions under which practices are enacted can be changed, and that we can build practice architectures that enable more than they constrain.

Drawing on the findings of this study, we might then ask three questions: How do we push at the boundaries of existing practice architectures? What are the conditions that enable research, policy, and practice to be mutually cooperative and agentic in teacher education? How do we combine action-oriented inquiry with the larger configurations of politics, power, resources, and capacity?

It is clear that the building of a relational architecture that can promote action as well as agency requires a deep appreciation of the primacy of practice and conditions on the ground. This implies more substantial attention to the complex (and expensive) processes of 
communication, dialogue, stakeholder forums, and policy commentaries to better understand the experiences, insights, and interpretations of those responsible for enacting policy proposals. In the instance of the PPSs research project, the research design needed, at the very least, to be more attuned to the material conditions of implementation, including resources and capacity.

The significance of this research lies in its location in a setting in which policy, research, and practice in teacher education are, unlike in many other countries, already working relatively cooperatively. However, more research is needed to understand the actions and interactions across these three domains, even where there is broad agreement and cooperation towards a common goal. Such insights will allow for deeper deliberation on the potential for a threefold contribution to teacher education —informed policy-making, engaged scholarship, and enhanced practice.

\section{Acknowledgement}

Thanks are due to Marie Brennan and Lew Zipin for the very valuable advice provided for my thinking through this study.

\section{References}

America, C., Edwards, N. \& Robinson, M. (Eds.), (2020). Teacher education for transformative agency: Critical perspectives on design, content and pedagogy. African Sun Media.

Ball, S. (1998). Big policies, small world: An introduction to international perspectives in education policy. Comparative Education, 34(2), 119-130.

Biesta, G. (2010). Why 'what works' still won't work: From evidence-based education to value-based education. Studies in the Philosophy of Education, 29, 491-503. https://doi.org/10.1007/s11217-010-9191-x.

Cain, T. (2016). Research utilisation and the struggle for the teacher's soul: A narrative review. European Journal of Teacher Education, 39(5), 616-629. https://doi.org/10.1080/02619768.2016.1252912.

Cain T., Wieser, C., \& Livingston K. (2016). Mobilising research knowledge for teaching and teacher education. European Journal of Teacher Education, 39(5), 529-533. https://doi.org/10.1080/02619768.2016.1256086.

Cochran-Smith, M., Villegas A. M, Abrams, L., Chavez-Moreno, L, Mills, T., \& Stern, R. (2015). Critiquing teacher preparation research: An overview of the field, Part 2. Journal of Teacher Education, 66(2), 109-121. https://doi.org/10.1177./002248711487114558268. 
Deacon R., Osman R., \& Buchler, M. (2010). Education policy studies in South Africa, 1995-2006. Journal of Education Policy, 25 (1), 95-110. https://doi.org/ 10.1080/02680930903314269.

Deacon, R. (2016). The initial teacher education research project: Final report. JET Education Services.

Department of Basic Education and Department of Higher Education and Training (DBE \& DHET). (2011). Integrated strategic planning framework for teacher education and development in South Africa. Government Printer.

Edwards, A. (2005). Relational agency: Learning to be a resourceful practitioner. International Journal of Educational Research, 43, 168-182.

Edwards, A. (2011). Building common knowledge at the boundaries between professional practices: Relational agency and relational expertise in systems of distributed expertise. International Journal of Educational Research, 50, 33-39.

Edwards-Groves, C., Brennan Kemmis, R., Hardy, I., \& Ponte, P. (2010). Relational architectures: Recovering solidarity and agency as living practices in education. Pedagogy, Culture and Society, 18(1), 43-54.

Gravett, S., Petersen, N., \& Petker, G. (2014). Integrating foundation phase teacher education with a 'teaching school' at the University of Johannesburg. Education as Change, 18(1), 107-119.

Green, B., Reid J-A., \& Brennan, M. (2017). Challenging policy, rethinking practice: Struggling for the soul of teacher education. In T.A. Trippestad, A. Swennen \& T. Werler (Eds.), The struggle for teacher education: International perspectives on governance and reforms (pp. 39-55). Bloomsbury.

Hammersley, M. (2013). The myth of research-based policymaking and practice. SAGE. http://dx.doi.org.ez.sun.ac.za/10.4135/9781473957626.n3.

Kemmis, S. (2009). Understanding professional practice: A synoptic framework. In B. Green (Ed.), Understanding and researching professional practice (pp. 19-38). Sense Publishers.

Kemmis, S. (2018). Life in practices: Challenges for education and educational research. In C. Edwards-Groves, P. Grootenboer \& J. Wilkinson (Eds.), Education in an era of schooling: Critical perspectives of educational practice and action research. A festschrift for Stephen Kemmis (pp. 239-254). Springer.

Kruss, G. (2008). Teacher education and institutional change in South Africa. HSRC Press. 
McLaughlin, M. (1987). Learning from experience: Lessons from policy implementation. Educational Evaluation and Policy Analysis, 9(2), 171-178. http://www.jstor.org/stable/1163728

McNicholl, J., Ellis, V., \& Blake A. (2013). Introduction to the special issue on the work of teacher education: Policy, practice and institutional conditions. International Research and Pedagogy, 39(3), 260-265. https://doi.org/10.1080/02607476.2013.799844.

Robinson, M. (2015). Teaching and learning together: The establishment of Professional Practice Schools. Stellenbosch University. Research report commissioned by Department of Higher Education and Training.

Robinson, M. (2016). Professional Practice Schools as a form of school-university partnership in teacher education: Towards a social justice agenda. Education as Change, 20(2), 11-26.

Rule, P., \& John, V. (2011). Your guide to case study research. Van Schaik Publishers.

Rule, P., \& John, V. (2015). Necessary dialogue: Theory in case study research. International Journal of Qualitative Methods, 14(4), 1-11. https://doi.org/10.1177/1609406915611575.

Sayed, Y., Carrim, N., Badroodien, A., McDonald, Z., \& Singh, M. (Eds.), (2018). Learning to teach in post-apartheid South Africa: Student teachers' encounters with initial teacher education. African Sun Media.

Sayed, Y., Kanjee, A., \& Nkomo, M. (Eds.), (2013). The search for quality education in postapartheid South Africa: Interventions to improve teaching and learning. HSRC Press.

Walton, E., \& Osman, R. (Eds.). (2018). Teacher education for diversity: Conversations from the Global South. Routledge.

Zeichner, K. (2010). Rethinking the connections between campus courses and field experiences in college- and university-based teacher education. Journal of Teacher Education, 61(1/2), 89-99. https://doi.org/10.1177/0022487109347671. 